\title{
Microsphere Adhesion on Rubber Films Accompanied by Sphere Sedimentation
}

Shoko Mishima and Toshiaki Ougizawa*

Department of Materials Science and Engineering, Tokyo Institute of Technology, 2-12-1

Ookayama, Meguro-ku, Tokyo 152-8552, Japan

*Corresponding author. E-mail: tougizawa@op.titech.ac.jp

\section{Supporting Information}
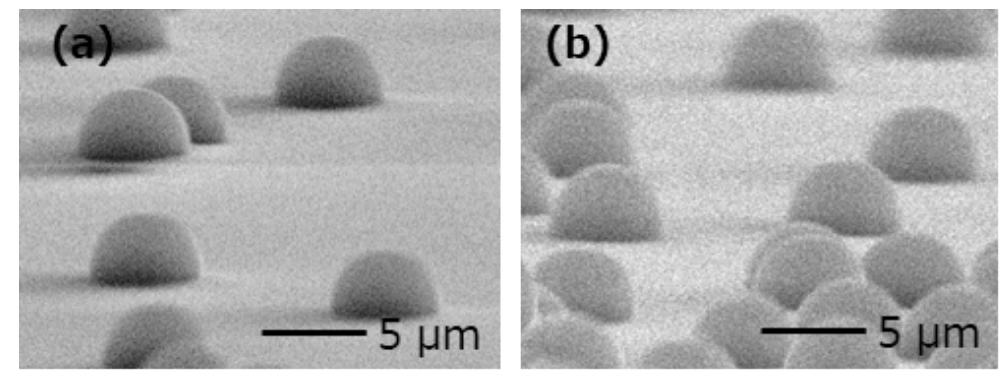

Figure S1. SEM images of the sedimentations of silica spheres (diameter: $5 \mu \mathrm{m}$ ) into an BR film (thickness: $160 \mu \mathrm{m}$ ). Resting time, which was from depositing the silica spheres until starting the sputter coating, was $45 \mathrm{~s}$. (a) Just after the sputter coating. (b) $24 \mathrm{~h}$ after the sputter coating.

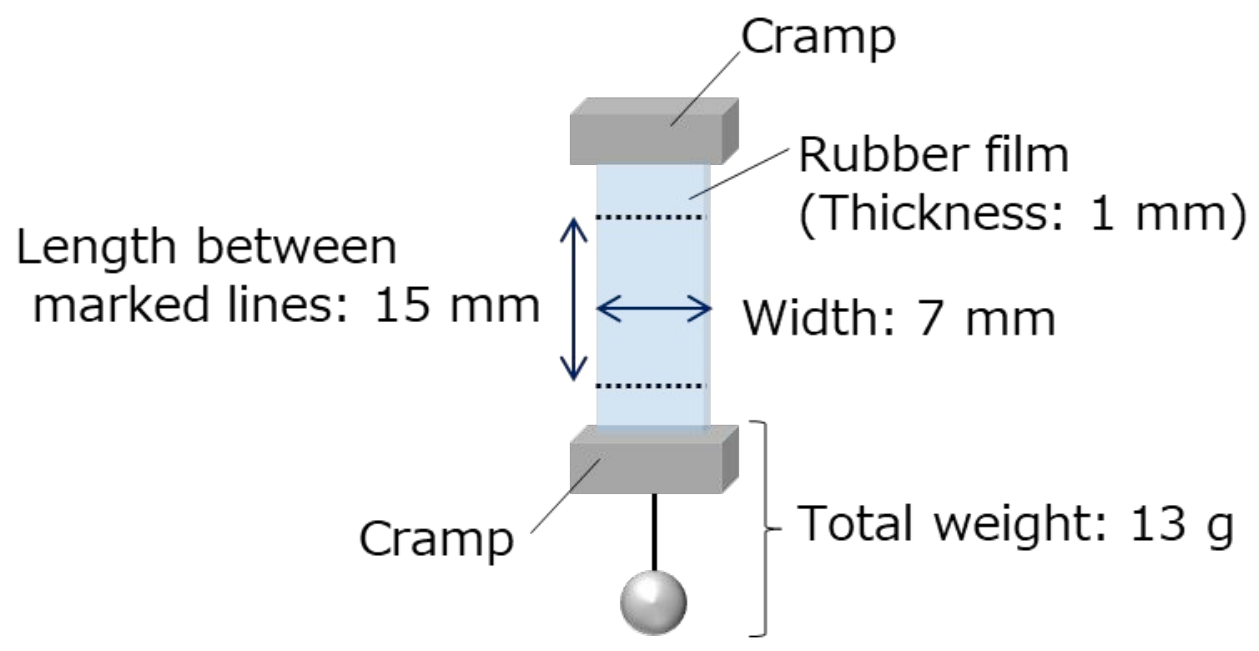

Figure S2. Schematic of an initial condition of the creep test. 